\title{
Improving the blend on a herbal medicine programme
}

\section{Rose Heaney}

\author{
University of East London
}

\section{Introduction}

Students studying the blended learning BSc Hons Herbal Medicine course at the University of East London (UEL) are a geographically dispersed group of mature learners, many of whom are already graduates in other disciplines. Most of their non-clinical study time, during which they have to develop an in-depth knowledge of the plant and medical sciences as well as of traditional herbal medicine practices, is spent off campus in self-directed learning. For several reasons, not least the fact that many of the teaching staff are remotely based part-timers, the distance learning aspects have tended to rely on printbased study guides with only ad hoc use of the virtual learning environment (VLE) and other technologies. Given the obvious inadequacies of this approach but also acknowledging the lack of staff resources to remedy it in the short term, internally funded initiatives ran from 2008-2010 to kick-start the systematic use of learning technologies on the programme. Key interventions and the associated evaluations are described below.

\section{The interventions}

\section{E-Assessments (anatomy)}

The introduction of formative e-assessment to two anatomy modules was one of the first interventions. The raw material was already available in the form of hundreds of unlabelled diagrams, delivered via PowerPoint, covering the various areas of general and systemic anatomy. Students would label the diagrams over a period of weeks and wait for the answers to be released on a set date. The disadvantages of this approach were quite apparent not least in the fi xed timing of answer release. These diagram labelling exercises were converted to Blackboard matching pairs questions, organised into topic based quizzes and made available to students at the outset of the module to be taken repeatedly at any time and in any order. The conversion process was not insubstantial but was essentially mechanical in that the questions and diagrams were all in existence already in the PowerPoint fi les. Quizzes consisting of multiple choice questions (MCQs) were also devised by the module leader to cover material of a more general nature on one of the modules. 


\section{Multimedia - basic clinical and dispensing skills}

Set piece videos to demonstrate the correct way of carrying out various clinical and dispensing procedures were produced with an easy to use video camera with high capacity hard drive. All video material has been provided on the Blackboard VLE in a range of formats both for online viewing and downloading.
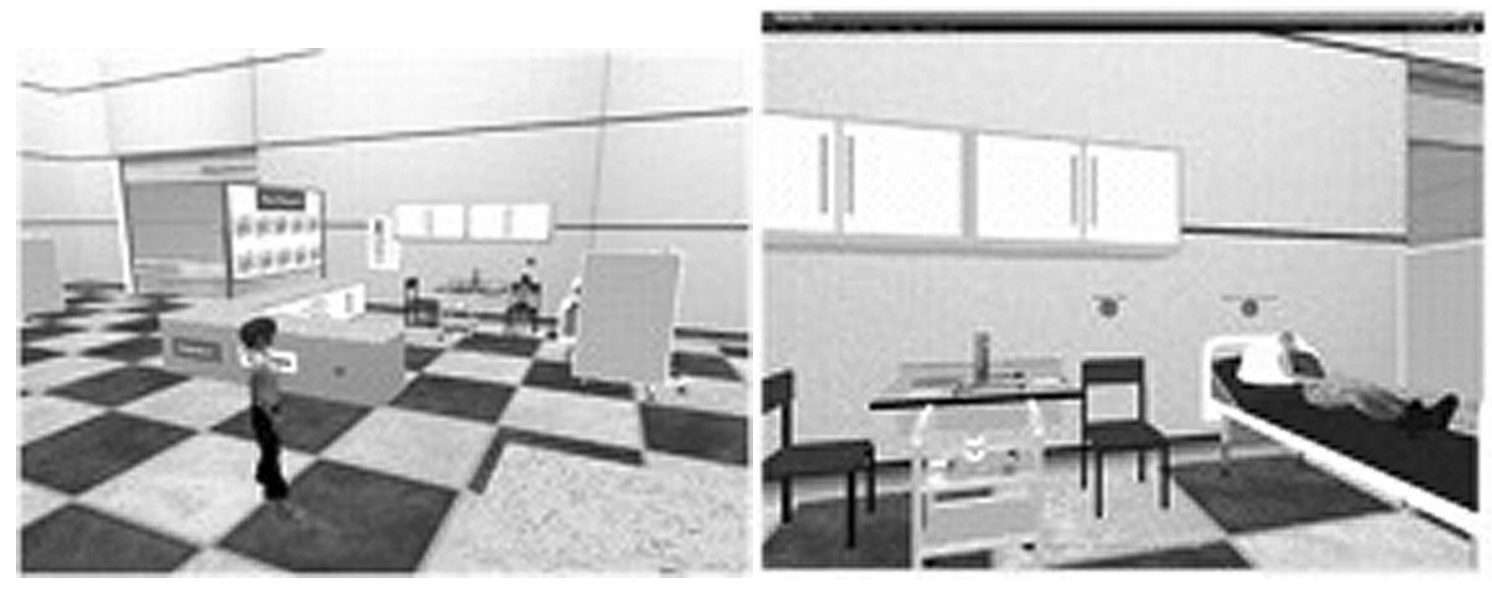

Figure 1 Second Life (SL) virtual patient

\section{Second Life virtual patient}

A herbal medicine outpatient facility (Figure 1) was developed within a multidisciplinary polyclinic on Health and Bioscience's Second Life (SL) island, UEL HABitat. The clinic consists of five separate bays, allowing students to work alongside each other on different cases. The object of the exercise is to establish a working diagnosis for a given patient using evidence gleaned by dialogue with the patient, who responds to pre-programmed triggers and from a range of diagnostic tools and test results implemented as interactive objects. Having assembled as much information as possible about the patient, the student takes a quiz to confi rm the validity or otherwise of their working diagnosis. Conversation with the patients and information returned by the objects is displayed in the SL text chat area, a transcript of which can be saved by the student for reference later. The quiz is web based and submissions are accessible by staff independently of SL. (For a fuller description of the virtual patient see Heaney 2010). 


\section{Summary of evaluation}

\section{E-Assessments}

Kruskal-Wallis and Mann-Whitney tests were used to correlate fi nal exam results with online assessment (MCQ and diagram matching questions) usage by two cohorts on one of the anatomy modules. Statistical limitations notwithstanding, the evaluation showed that breadth of use of the online assessments related to improved exam performance.

Initially it was found that scores for the 08/09 cohort in the short question section of the exam were positively and significantly correlated to MCQ use online. Use of the diagram matching questions did not seem to have a significant impact on the diagram section of the exam, although the trend was positive. When the 09/10 cohort was added, the diagram section of the exam seemed to be the one that was improved by use of the matching questions. The overall exam scores were also improved when online tools were used, but not significantly so. Online MCQs did not seem to have much of an effect on exam results, but they were not used as extensively as the diagrams.

The most supportive finding was that, overall, increased use of the online tools by the 08/09 and 09/10 cohorts correlated significantly with their scores on the diagram section of the exam and also with their total exam scores.

The material on the videos was explained clearly and concisely.

The content of the videos complemented what had already learned in clinic.

The material on the videos was organised effectively.

The procedures on the videos were demonstrated very well.

I really enjoyed watching the videos.

The videos were boring.

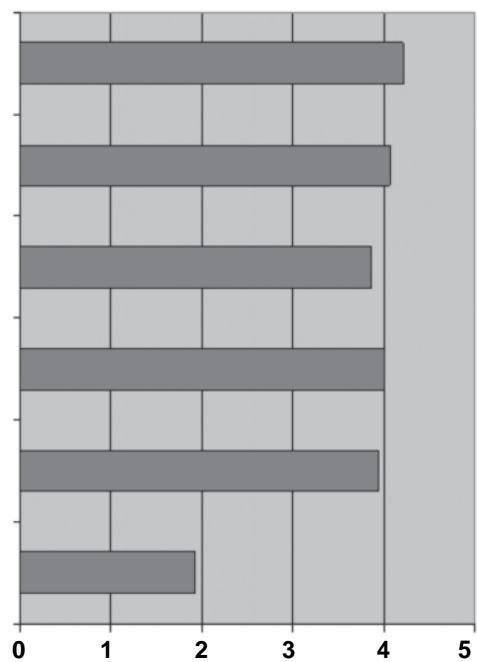

Figure 2 Sample of online survey

Qualitative data obtained via surveys, interviews and focus groups reveal that most students like quizzes as revision tools and would like to see them in other subject areas. 


\section{Multimedia}

The clinical and dispensing videos were not module specific so the type of analysis used for e-assessment was not applicable. We devised a 24 question survey using Likert-type scale $(1=$ strongly disagree, $5=$ strongly agree) with some free response questions and also ran several focus groups.

There were 14 responses to the online survey of which Figure 2 is one section and typical of the other section responses. Survey and focus group results point to an overall positive reception of videos with quite a few suggestions for improvements. The majority agreed that the videos were useful as a learning tool, although only as a revision tool and not as a substitute for real practice, which was never their intended use. Another significant point made by some students was that the videos were particularly useful as a guide to the exact protocol required of them in clinical examinations, something which could not be assumed when viewing similar resources such as YouTube or similar sites.

\section{Second Life (SL)}

The use of the SL virtual patient is in its early stages but preliminary data from focus groups and surveys of the pilot group indicate that it has been a qualifi ed success. Virtual worlds such as SL present barriers as well as benefi ts to both staff and students (Warburton, 2009) so an overwhelmingly positive response at this early stage would be unlikely, particularly with this programme's demographic of mature and technologically conservative students. The herbal medicine students were the fi rst to use the SL virtual patient so their feedback was very useful in informing the next iteration which is now being used by physiotherapy students. Heaney et al. (2010) provide a more detailed evaluation of the prototype virtual patient.

\section{Reflections}

The development of e-assessments of the type described here may well be frontloaded, particularly if the questions need to be designed from scratch, but any such investment will reap benefits in the future - the anatomy quizzes, which are now in their third year of use, have required very few adjustments to remain as relevant and useful as before.

A perennial complaint of students on this programme is that they do not receive enough feedback, but on closer investigation we have established that rather than formal feedback from teaching staff, what they are really requesting is a means of self-assessment on an ongoing basis. Hence our anatomy quizzes, one form of which gives question by question feedback, have been well received and are illustrative of the benefits widely acknowledged (e.g. Ross, Jordan and Butcher, 2006) on use of e-assessment to provide feedback to remote learners. 
Over the two year period since the multimedia development commenced, easy to use, cheap devices such as flip cameras and MP3 recorders have become available, making it possible for staff to generate more resources themselves, without requiring the expert help and expensive equipment which had hitherto been the case. We are therefore optimistic that the production of this type of resource will become more integral to normal practice.

Development of the SL polyclinic with its virtual patients has been a very resource intensive exercise and only possible because other subject areas were involved. It is worth highlighting the benefit that programmes such as herbal medicine with small student numbers can gain by joining forces with colleagues in related subject areas. One other point of note is that virtual patient simulations, whether in SL or other platforms, are a very valuable addition to any clinical programme where student access to real patients and diverse conditions is of necessity limited.

\section{Conclusions}

The generally positive experience of the interventions to date provides a basis for further developments across the programme. However in the current economic climate the focus needs to be on those that are manageable by academic staff without high levels of specialist support. A recent example of selfsufficiency is of a member of staff based at a remote location who managed to produce a series of quizzes in a format easily importable to the VLE and some multimedia resources, having been sent a flip camera and MP3 recorder and some simple e-mail instructions.

We need to continue to evaluate the effectiveness of existing and new resources using a mixed methods approach where possible though mindful of the fact that small cohorts, as are typical of this programme, make quantitative analyses of the sort we attempted with the e-assessments quite difficult.

Another key aspect of any future development is to continue to support students well in the implementation of new initiatives. In the case of the e-assessments and multimedia, we provided VLE discussion areas where students could report faults and help their peers solve issues related to usage, e.g. downloading videos. We offered all students face-to-face induction in the use of SL virtual patients, without which most of them would have struggled.

Finally, opportunities need to be actively sought to ensure staff on the programme are aware of what colleagues are doing, so good practice can be disseminated and shared. This is a particular challenge on a programme where many of the staff are based remotely, rarely attend campus and are only employed for a limited number of hours per semester. 


\section{References}

Heaney, R. (2010) Virtual Patient Developments. Available at:

http://blog.uelconnect.org.uk/hab/2010/06/17/virtual-patient-developments-june-2010/ (Accessed: 10 January 2011)

Heaney, R., Timmins V-S., Booth, P. and Dawes J. (2010) 'Student Perceptions of a Second Life® Virtual Patient to Complement More Traditional Forms of Clinical Education' ECEL 2010: 9th European Conference on e-Learning. Instituto Superior de Engenharia do Porto, Porto, Portugal, 4-5 November 2010. Reading: Academic Publishing Ltd, pp 236-243.

Ross, S., Jordan, S. and Butcher, P. (2006) 'Online instantaneous and targeted feedback for remote learners.' In: Bryan, Cordelia and Clegg, Karen eds. Innovative assessment in Higher Education. Routledge/Taylor and Francis, pp. 123-131.

Warburton, S. (2009) 'Sec ond Life in higher education: Assessing the potential for and the barriers to deploying virtual worlds in learning and teaching', British Journal of Educational Technology, Vol 40, No.3, pp 414-426. 